\title{
SIGN LANGUAGE AS A FIRST LANGUAGE: SOME EXPERIENCES OF A HEARING CHILD OF DEAF PARENTS
}

\author{
Wenda Walton
}

\begin{abstract}
This paper relates some experiences of a hearing person who has grown up with Deaf parents who use New Zealand Sign Language (NZSL) as a primary mode of communication. It describes some of what it is like to be hearing in a Deaf community. It also describes experiences of being in a hearing community while being raised by Deaf parents. This includes what it was like to know both English and NZSL when few others did. Finally, as a qualified NZSL interpreter, issues of being both an interpreter and Deaf community member are introduced.
\end{abstract}

\section{INTRODUCTION}

I grew up bilingual, having learned sign language from my parents before learning English from hearing friends and family. Both of my parents went to Deaf schools in New Zealand. Dad was born Deaf and Mum went Deaf at age three from meningitis. At school they used sign language with other Deaf children, but with teachers they used the 'oral method'. As adults, New Zealand Sign language is their preferred language.

My parents went to residential schools only for Deaf children from the time that they were five years old until they were sixteen. They both started school in the early 1950s. My father went to Sumner School for the Deaf, now known as Van Asch Deaf Education Centre, and my mother went to St. Dominic's School for the Deaf in Fielding, near Palmerston North.

For them, involvement and relationships with many other adult Deaf (called the Deaf community) was a natural flow on from relationships already formed in school. My father has been involved in every committee involving Deaf affairs that I know of, barring any women's committees. In his younger days, he 
was a keen and skilled sportsman in both hearing and Deaf circles, playing representatively, so sporting committees were popular for him. He has also been equally involved in Deaf Club and Deaf Association of New Zealand committees or boards. My mother was not involved in committees as much because she was rearing my brother and me. She was a busy Mum, taking care of two energetic and rowdy children. While Dad would go away overseas for weeks at a time, and spend evenings out involved in various committee meetings, Mum would do everything else that needed doing on her own.

My father's initial training was in joinery and cabinet making. While growing up he partnered in a few businesses with both hearing and Deaf people. However, most of his career has been spent working for a bigger shop fitting company in which he eventually became foreman. He now works as a manager in a residential school for Deaf students in Auckland.

My mother, after an initial time home with us young children worked as a machinist for a similar length of time as my father spent in joinery. Since finishing as a machinist she has studied outdoor adventure tourism, worked with Deaf students of all ages in the compulsory education sector, and worked with Deaf adults in the Deaf community.

Both my mother and father felt in the past that opportunities for Deaf people were limited so that they could only do manual work. They see now that opportunities are broadening for Deaf people in employment. This is reflected in their changing employment situations.

When my brother and I were born, doctors advised my parents to use speech instead of sign language with us. Despite the advice, they signed with us. I imagine that this is because signing worked where speech did not. Dad used his voice while signing with us, while Mum did not. I am not sure why, but it made no difference to our communication either way.

When I was around five or six years old I remember finding myself looking up at a puzzled teacher. I had approached her asking how to spell a word.

'How do you spell xxx Mrs Creasy?'

'Pardon?

'How do you spell xxx?'

'Say it again for me dear.'

'Xxx, you know!'

'I'm not sure I know exactly which word you mean.' 
'Xxx,' I said in my clearest speech.

'Hmm, no, sorry dear.' She looked a wee bit embarrassed, and I felt confused.

'Why didn't she know that word?' I thought.

Quietly we went in opposite directions before the bell rang for playtime. I do not remember the word I was wanting, but I can guess what it may have been. On Friday mornings at playtime I remember the usual boasting round on the monkey bars. 'We had fish and chips last night!' piped up Vanessa. 'Well, we had Carburger!' I would proudly retort toward the faces of a few puzzledlooking kids.

It is not surprising that I used the word 'carburger' rather than McDonalds. My father would sign, simultaneously using his voice, 'Do you want hamburger for tea?' I knew the sign for 'hamburger', and knew what it meant, but his voicing sounded like 'carburger' to me. Naturally, I thought that 'carburger' was the English equivalent for what people knew as McDonalds. Bishop and Hicks (2005), in their article 'Orange Eyes: Bimodal Bilingualism in Hearing Adults from Deaf Families', discuss the situation of educators who are not aware of bilingual issues for children with deaf parents. Signing is often not acknowledged as a language. Children have, therefore, been labelled as having language difficulties when such situations may be due to interlanguage factors.

While I was not labelled as having a language difficulty, the miscommunication I have described here was common. These miscommunications, however, were the least of the differences that I recall and think about now. In this paper I present some of my experiences, growing up as a hearing child with Deaf parents, that impact on interpreting and being an interpreter.

SOCIALISING

In my family when you wanted to visit someone you just did. Mum and Dad did not have access to the technology to contact their friends, unlike hearing people who could use the phone. Most Deaf friends worked all week with their hearing work mates and had few chances to talk, so I suspect that when Mum and Dad showed up at friends' places in the weekend they were pleased to have some real conversation. Mum and Dad just drove to friends' houses whether they were expected or not, and their friends did the same. If people were not home, then they would leave a note saying that they had been there. This seemed an easy social arrangement. 
Amongst my own hearing peers I found knowing the rules for social engagement a bit tricky. For instance, I was not sure how to call my friends to ask if they wanted to do something. For a long time my friends would just call me because I never called them. We did not have a phone until I was eight years old. Apparently, with some friends, it was rude to turn up uninvited to their house. Such rules of conduct fell outside my area of expertise. I never witnessed my parents negotiating social visits - they just visited. I am sure that they would negotiate future visits when they met with friends, but to 'overhear' these conversations I would have had to look at them, instead of play. When friends called and said that they were coming over, or they just dropped in, I felt like the wind had just dropped and I could walk more upright. Now, however, as an adult I feel socially more comfortable with hearing people, particularly since I've been part of my own adult 'hearing' community.

At school I often felt different. I would make friendships more easily with those people who also seemed different, like the naughty ones, poor ones, Polynesians, and Asians. I gravitated to people that I did not feel abnormal around, much like any child would. If there were children with Deaf parents I may have gravitated to them.

A few things made me feel different. Teachers would often ask me about having Deaf parents and using sign language. Children would also ask lots of questions like, 'Can your Mum and Dad talk? Work? Drive?' A few would have a go at their own versions of sign language. Some would use it mockingly. Another difficulty I had was with communication when I started school. It could be confusing. I remember a few times ending up in the wrong place for classes. This possibly contributed to my feeling very aware of myself and my situation. I remember at seven or eight years of age counting how many years I had left at school!

Paul Preston who is a son of Deaf parents wrote a book called Mother Father Deaf: Living Between Sound and Silence (1995). His research involved 150 adult children of deaf parents. Several hearing children in Preston's research commented that people would give either negative or positive attention when they realised that the parents were deaf (1995:172): 'It was like clockwork. Sooner or later every teacher I had would have me come up to the front of the room and tell the class: what was it like to have deaf parents. Show us some sign...I got to be the centre of attention.' This was also my experience. 
Up until the mid-1980s, when I was ten years old, there were no trained NZSL interpreters in New Zealand. I was at my Nana's place one morning and three people turned up in her lounge - one Deaf guy, one hearing guy and a pleasant looking blonde-haired lady. Just then the hearing guy started swearing in English at the Deaf guy. Nana must have been off making cups of tea. (She never swore.) Then the blonde-haired lady joined in. She started saying exactly what he was saying but in sign language - even the swearwords. It was like there was a different lady in the room. All I could think was, 'How could they talk like this to this Deaf guy?' I had known him from I don't remember when, and he seemed alright to me. I decided that I did not like the other two much. Later I learned that the swearing wee lady was an interpreter, the first proper one to come to Wellington.

Interpreting, as a formal activity, was something that I became aware of when I was ten years old, in 1985, when professional interpreters first became available. This is when my parents started talking about them to me and I started seeing them around. Up until then it was not a job title, it was just part of being in our family. Many things happened in place of interpreters, a lot of which included family members and friends. When I was around seven years old I remember desperately wanting the mantle of making phone calls for Mum and Dad like my older brother had. It is common for the eldest child to be the main interpreter in the family, unless the elder is male, then it is often oldest female child (Preston 1995:100). This rings true from what I have seen personally. 'Interpreting is perhaps the one feature most associated with hearing children of deaf parents' (Preston 1995:142).

According to Preston (1995:150) children in his study responded to this thing called interpreting and other related tasks differently. Some children accepted that it was just what happened, while others found it more difficult.

As I grew older I became more involved in a variety of settings in which I 'interpreted' for various lengths of time. This would include making phone calls and helping Mum and Dad talk to shop keepers. This could loosely be called interpreting. Looking back, I can see that I used several interpreting 'models', including the nosy model, the careless model, and the interfering model. These models are not actual models used in interpreting. They seem, however, to describe well the kind of 'interpreting' that I was doing at any one time. The one I used depended on my personal interest in the situation, my mood, and my willingness to interpret. I make no apologies for any of them! 
I often chose to interpret, like when Mum and I would go into clothes stores. Sales people would typically approach Mum's turned back and say, 'Good morning, lovely day isn't it?' This was a cue for me to step in and try to throw my voice, 'Yes, thank you.' Or if I was feeling energetic I would run up to Mum, tap her on the shoulder, and tell her what they had said. She would respond by turning, nodding and smiling at the sales person, but often by this stage the sales person was confused or embarrassed. They were probably experiencing a time delay in their mental processing. A Deaf person using sign language always seemed like a novelty to others when I was young. Maybe they just were not very well advertised.

I was not always within convenient running distance of Mum, however, so often I would only see the miffed faces of store staff glaring at the back of my mother's head. The glares mostly said, 'How rude!' Sometimes I found this funny, sometimes not. If not, I liked to say loudly, 'She's Deaf.' I would then be pleased to see the miffed look vanish beneath a red veil of embarrassment. Alternatively, people would apologise then start asking me questions referring to my Mum or Dad, 'Can they drive? Is that your friend? Sign language is so beautiful, where did you learn it, did you teach your friend?' 'Umm, she's my Mum and she taught me,' I would reply.

At other times interpreting was not self-motivated but rather like doing dishes or going to bed when it was still light. Sometimes I would complain, sometimes I would just do it.

I could be a very reluctant interpreter. This was especially so in cumbersome situations where Mum or Dad would want me to say something that I did not want to. Once while we were on holiday Dad got angry at the expensiveness of a theme park fun ride. He told me to tell the counter staff that they were daylight robbers. I was very embarrassed and refused, despite Dad's urges. Generally, I think I refused to interpret because I thought that some comments might be considered rude or inappropriate. Whether my assumptions were right or wrong, I am not sure. It is also not common for a young person to say adult things. For example, children are usually not as assertive as adults are. I was probably also motivated by impending shame, which children have extra doses of when it comes to their folks. I particularly related to one of the participants in Preston's research who said (1995:54): 'One time he [father] was just furious at this [store] clerk. My dad told me to tell the guy to shove it up his ass! I remember saying something like, well, my father doesn't think this is a good idea.' 
It worked the other way, too, often in an opposite fashion. When hearing people said rude or inappropriate things I liked to tell my parents so they could glare or hopefully tell me something witty or cheeky to say back.

Most of my peers with Deaf parents interpreted for their folks when they were growing up. Some children interpreted regularly for their parents' hobbies so that the parent could participate. Some interpreted for parents at the police station. Most of us interpreted the usual everyday stuff like helping translate letters received in the mail, snippets of TV news, and door salesmen's monologues. This was the bulk of it. As adults most of us complain about having had to do it. But when we were young we seemed to just get on with it. The biggest complaint we had was that we hated being relied on - indispensable. We hated the fact that a lot of the time when our parents approached us it was to ask a 'favour'.

I have come across a few Deaf parents who see their children as their own personal interpreters even though there are professional interpreters available now. Once a dad said to me that when his children grew up he looked forward to them interpreting for him. He wanted them to tell him when someone was knocking at the door and then to interpret for him. I was disturbed by his comment and told him that children were not to be interpreters. They were to be children, and if he needed an interpreter he should book one. I guess that reflected my negative attitude, at the time, at having been an interpreter for my folks. Now the world seems less black and white, but I still believe that children are best left out of their parents' affairs. This is so that they do not have the potential to feel unnecessarily responsible for adult issues, nor indispensable in their parents' lives.

There were not many options for communication between my folks and hearing people and therefore little understanding between the groups. My parents, though they had contact with hearing people, would not always understand what they were saying/doing or why, so at times, we became little 'guides on hearing people', as well as interpreters, in direct and indirect ways. My brother and I were among the few people that Mum and Dad knew who were conversant in both their language and English. We were also the closest. This experience echoes the name of an article that Linda Konner (1987), a woman with deaf parents, wrote. She called her article, 'I Was My Parents' Radio'. Bishop and Hicks (2005:190) also describe how 'children often become the intermediaries between their parents and hearing people'. 
Knowing more than my folks, about English and other things in regard to the hearing world, led me to believe that generally I knew more than my folks did. Now, I know that this is not true. But then it translated into the idea that if I knew more than they did, how could they help when I wanted to know anything? The thought that I was the end of a knowledge pathway in my immediate family was isolating at times.

TWO COMMUNITIES

There is a hearing world and a Deaf world. The demarcations between the two are indicated in many ways. In Deaf sports you can usually play only if you have a certain decibel loss. In Deaf communities there are many jokes about hearing people, not being able to hear things and the havoc it can cause. When Deaf people meet you they almost immediately ask if you are Deaf or hearing. If you were not Deaf but could sign, I got the feeling that it was ok, but not as good as being Deaf. I do not have the experience of being Deaf, only of being raised by Deaf and learning the language.

Other hearing children have also felt that Deaf see them as 'hearing' - from another culture though raised by Deaf people. Preston (1995:195) uses the following illustration: 'This deaf man asked me if I was deaf or hearing. And when I told him, we just kept on talking about stuff. But it was like he needed a basis upon which to interact with me or judge me'

But yet we are not as 'hearing' as other people. In the words of one of the participants in Preston's (1995:196) study, 'My mother would go on and on about how she could never trust hearing people. And I looked at her and said, 'Well what about me? I'm hearing.' And she looked at me and said, 'No, I didn't mean you. You're different.' This way of thinking refers to my experience that I describe as being 'in between'.

I imagine that my parents thought the experience of being Deaf did not need to be passed on to me because of the assumption that my life, as a hearing person, would be different from theirs. It seems a fair assumption to me. If one of their children had been deaf, however, they may have viewed things differently. Being hearing automatically means that my life experience will be fundamentally different. I will not go to a Deaf school or class. I will not be a minority group in a majority culture. Nor will I have to deal with the everyday logistics of not hearing things in a society largely set up for those who can hear. 
I actually wanted to be Deaf. When I was younger, about five years old, I went through the regular school nurse eye and ear checks. The test results came back indicating that I needed to see the hospital audiologist. I remember sitting there, with the drumstick I needed to tap when I heard a sound through my headphones, pretending I could not hear random sounds. I had also done this with my school test. I was disappointed when the results were that I was only mildly deaf.

I think that my parents, as well as many other Deaf parents that I have heard about, had an erroneous perception of what it meant to be hearing. Several friends with Deaf parents humorously quote their parents as saying, 'Of course hearing know everything because they can hear, why don't you know, you're hearing aren't you?!' This seems to mirror exactly the words of another of Preston's (1995:197) participants: 'My parents kept telling me, "You should know everything, you're hearing." How come I'm supposed to know everything? Just because I'm hearing, they think I know everything. I don't know.

Before the six oclock news was captioned I remember Mum or Dad asking what was being said. But often I could not understand what they were saying even though I could hear it. One series of news items I vaguely recall was about the fighting going on in Libya. I did not understand the words they used, the history to the event or why people might be fighting. This did not help. Mum and Dad were surprised that I did not understand and I think found it hard at first. Another time my Dad asked me to interpret for a workshop at a conference when I was fourteen. He looked puzzled when I suddenly stopped trying to sign and told him that I did not understand.

My parents would not have had many real opportunities to discover what it would be like to be hearing, and how much hearing people could really know despite being able to hear. I know that their perceptions would have been influenced by the education with which they were presented. Basically, they said, much of the focus was on being able to use any residual hearing they had and mastering lip reading. Being as 'hearing' as possible was the aim. It would not be hard, then, to assume that if you are actually hearing you will have success. Signing was banned and real education was limited.

Despite being hearing I have a definite sense of being part of the Deaf community. My Dad used to tell me that I was Deaf with a capital 'D', meaning culturally Deaf. Not being deaf, he wanted me to be at least an honorary Deaf person as a consolation prize. I remember being flattered, though I did say 
that I could not be Deaf, thinking that being able to hear definitely disqualified me. I would remain as an honorary Deaf person just to him.

With Deaf I find it easier to be myself in many ways. This may be because much of my identity and personality was formed around Deaf people. When I am with hearing people I can feel like a completely different person.

I also feel at home being 'in between'. I tend to laugh a lot with hearing friends who also have Deaf parents. My parents have very good friends who I call my Deaf aunt and uncle, and their children my cousins. One major reason for being at home with them is how much I feel I relate to them. I know many experiences we have will be similar but yet different to most of our peers. I think the 'in between' category is a very good one, but there are few of us, and we are quite geographically distant and even then we may not necessarily be friends.

Many adults in Preston's (1995:198) book speak of the struggle of being hearing but feeling Deaf. The following comments epitomised this idea: 'I always felt like I didn't belong either place. I didn't belong with the Deaf 100\% and I didn't belong with the Hearing. I didn't feel comfortable with Hearing. I felt more comfortable with Deaf, but I knew I wasn't deaf. I feel like I'm somewhere in between.' And (ibid:236), 'I'm not Deaf, but I'm not hearing. [Signs, I don't know, I'm not deaf or hearing. Both, I guess.]'

Preston (1995:236) expresses this ambiguous position suggesting that we are different and we are the same. We are not deaf. We are not hearing. We are neither deaf nor hearing. We are both deaf and hearing.

I accept my difference and sameness. It does not affect me to be a mixture or lolly scramble. It is not important to me whether hearing or deaf people think that I belong. I know that I belong in part in many places, and not just in the two categories of deaf and hearing. While I used to be a bit confused about this, now I quietly accept my unique position.

NOW AS A PROFESSIONAL INTERPRETER

I finished my interpreter training when I was nineteen years old and went to work full-time and later part-time as an interpreter. I have also studied the Arts, achieving a Masters in Applied Linguistics. In between I have worked as a researcher in the Deaf field and a tutor in the Deaf Studies Research Unit at Victoria University in Wellington. 
Interpreting is a job that I have felt compelled to do. I do not think that it would be simple to say why. Like any other job it can be satisfying and very interesting. It can also be difficult and tedious. The good and hard bits are so for many reasons.

The benefit of interpreting now versus what I did when I was at home is that it has a ring around it in several ways. In other words, I have structure around my role as an interpreter. For instance, I know where my role starts and finishes. While interpreting I know what I can and cannot do. This is guided by a set of professional ethics. (See Shannon Knox's paper in this collection for a discussion of the interpreter's code of ethics.) Another benefit is that when family or friends ask me to interpret I am free to do so, or to ask them to book another interpreter.

Interpreting is an unusual job. Largely, for me it is to become a vehicle for other people's lives. By 'vehicle' I mean the entity through which people can, in general, communicate and therefore carry out their every day lives. Interpreting is the skill I use as this vehicle. For instance, I will interpret for doctors' appointments, university lectures, and counselling sessions. These are activities that I may be personally involved in at another time. But, while I am working I am there for the communication benefit of the two parties, not myself. Naturally, there are benefits while interpreting, but these are unusual benefits, such as learning a new word or phrase. I also benefit by learning more about the society I live in. However, these are benefits that I do not directly strive for, they are incidental to doing the work. My core job does not mean striving to finish projects by a certain deadline, negotiating, stating my opinion, or seeking from others things that will directly benefit me. The aim is to be the best interpreter that I can be so that others can fulfil their needs and wants.

As one of Prestons' (1995:102) participants said: 'It doesn't matter that I'm forty years older than these children. My job is to be their voice... When I'm the interpreter, I'm just the voice of an eight-year-old kid.'

Sometimes I feel drained of my personality in this role. At times I find it hard to stop talking when I see friends or family. Much of my day may have been focusing on expressing others' personalities. I know that I am not a personality-less worker that has no creativity in the job I do. There is creativity in the interpreting task. But interpreting is, almost by definition, not the job for personal expression. To me its aim is to convey more of others' personalities and less of my own. This can be a stifling feeling but it is the nature of the job. It can have its advantages too. 
Knowing English and NZSL well are obviously important to being able to interpret, though there is more than just language proficiency involved in interpreting. I have an advantage in my work because of my background. Being exposed to Deaf people much of my life has meant that I have had considerable exposure to how Deaf talk about and express themselves in their world - in NZSL and Deaf culture. Obviously I do not know everything there is to know about every sign user in NZ, but what I have been exposed to has helped me hugely.

When I first started interpreting I took my background and exposure to NZSL for granted. It was just something that I knew. Through seeing people learning NZSL and finding it challenging, I have now become more aware of what I know. I have also become aware that there is more to learn: my parents and the community's ways of expressing NzsL does not stagnate. NZSL grows and develops, as does any language.

Because language changes constantly, the need to keep up with it is important. I think this is crucial to becoming a better interpreter. How this is done is just as important. It is helpful to learn NZsL and culture through study, but authentic NZsL learning comes through seeing what people actually use in everyday life and interacting with that personally. Some NZSL learners that I have met have been annoyed at the language use they see by some Deaf people and say that it is not proper NZsL. It may have been seen as ungrammatical, or some facial expression used may not have been clear, for example. It can be easy to forget that hearing people learn NZsL in a way that most Deaf people do not. Deaf may have been exposed to NzsL earlier or later in life, learned it or not learned it from peers, had good or bad language role models and so on. Hearing people go to a class to learn a systematic version of NZSL that is presented as the language of New Zealand Deaf. The class version will be a representation of NZSL, but there will always be more richness and depth in the everyday life of signers.

Deaf people may not use sign in the ways that interpreters or students might expect. I think it is unhelpful to presume that they should. We too, will not know the signs they use. NZSL has to be a live language rather than one taught to curriculum standards. If perceived non-standard use of NzsL starts inconveniencing my job as an interpreter, then that is usually an indication that I am trying to fit a square peg in a round hole. The situation may need to be addressed instead of the person.

Starting off as an interpreter was not easy. I was to go from being the daugh- 
ter of Deaf parents to being a NZsL interpreter. Before I graduated I made a conscious decision not to return immediately to work in the city where I grew up. This was mainly for the purpose of establishing myself in the new role of an interpreter. Being in a familiar environment would have made this difficult for me and other Deaf. I would too easily be seen as so and so's daughter. I was also concerned that I would slip into bad habits if working for familiar people. I thought that it would have been difficult initially to establish confidence with Deaf people. I could imagine them wondering whether they could trust me to remain confidential in my job. However, I wanted to be near family and near enough so Wellington Deaf would see that I was now an interpreter. I worked in the Palmerston North Deaf community for two years before moving back to Wellington. Back here now, I am comfortable with both having grown up here and being a community interpreter. It has helped that the community has changed, and there are many people living here now who I did not know growing up.

For me, interpreting and friendship and/or community involvement are not mutually exclusive. Whether working as an interpreter, or not, I see myself as at least a fellow community member with Deaf for whom I interpret. I cannot stop being part of a community even when someone I am interpreting for is standing trial for a serious crime. My role will change, but my status will remain the same. When I am in the interpreting situation most Deaf know that my role changes, and I see that theirs usually does, too. They do not treat me familiarly for that time unless they are having me on. If they do find the role change difficult then I will manage this by not behaving familiarly at all. For instance, when I see some people at the Deaf Club I will not initiate conversation, though I will say hello if it seems natural to do so. Sometimes it will be a temporary thing, maybe during a period when I am interpreting more for them. It may be more long term. It may be that I interpreted for someone five years ago but behaving familiarly still seems uncomfortable. I am happy with this and understand it.

Sometimes I have fleeting urges to stop working as an interpreter because I see that my professional role limits my personal involvement with some Deaf people. This is a rare feeling, and it always involves another dilemma of choosing between two useful and good roles: interpreter and friend. The difficulty comes when I may be involved in interpreting for a person who is also a friend with more personal issues than even friends may want to share with each other. This is where I will hold off from initiating any friendship aspect of our relationship. I am the one who has been in the privileged position, so I will wait for them to start up our friendship again. When this happens I do 
not mind because to me being a friend or fellow community member means being there for one another. In a way interpreting means just that.

In many ways being an interpreter naturally involves me more in the Deaf community than if I was not one. I have a job to do in this community and feel as if I more naturally fit in as an interpreter than as an honorary Deaf person.

\section{DISCUSSION}

My own experience of having Deaf parents is of course unique and yet also not uncommon. The unique aspects are obvious. I am the only Wenda that has ever existed, and the same is true of my parents. Not only that but every situation and experience I have had with my parents has had a multitude of variables layered on the uniqueness we have. The commonalities are that many children with Deaf parents question their identity: am I Deaf or hearing? There is also the feeling of difference from others. This is exaggerated by being treated as different. Interpreting for parents also seems standard. This is viewed in a variety of ways depending on who you are. Then there is interpreting in the adult Deaf community after having grown up with Deaf parents.

Paul Preston (1995:4) focuses on two features common to all cultures: communication and families. Within this he explores questions specific to hearing children brought up by Deaf parents, such as:

- How important is auditory language in any child's development?

- Are traditional family roles functionally adaptive or intrinsically damaging?

- How do hearing children of deaf parents make sense of their family history?

- To what extent do hearing children of deaf parents have collective identities?

The information that he uses to explore these questions was based on stories 'that wouldn't ordinarily be told, the kinds of things that hearing children of deaf parents only tell one another' (Preston 1995:7). These are the sorts of things that I have shared in my story.

I have made sense of my experience using the idea of 'in between'. While he emphasises the multiple cultural perspectives in relation to Deaf culture and what happens when cultures collide, my focus for understanding my experience is what happens in the space between these cultural connections. Like 
him, I have told my story using fragments, but mine are drawn from both the Deaf and hearing worlds whereas his are mainly drawn from the Deaf world.

Bishop and Hicks (2005:188) talk about hearing children from deaf families as a 'relatively invisible linguistic and cultural minority'. Like the Children of Deaf Adults (Codas) described in their paper, I grew up in the Deaf community and learned NZsL as my first language. My story illustrates some of the points that they identify for hearing people who are bilingual and bicultural. It shows some of the ways in which I blend my sign language and English. There are also parallels between my story and some of the 'stigma [that] manifests in language attitudes and cultural identity' (Bishop and Hicks 2005:189) - I was happier with children who came from different cultural backgrounds.

When I read this paper the description of 'Coda writing' and characteristics of 'Coda-talk' were familiar. Yet identifying as a Coda is something that I pull back from because I feel that it excludes people who also have a right to be linked to the Deaf community. These may include friends, hearing parents, and siblings of Deaf people who are bilingual and bicultural. Coda seems to mark a territory overlapping with, and claim closeness to, the Deaf world that is different from the position in between worlds where I feel comfortable.

\section{REFERENCES}

Bishop, M. and Hicks, S. 2005 'Orange Eyes; Bimodal Bilingualism in Hearing Adults from Deaf Families', Sign Language Studies, 5 (2): 188-257.

Konner, L. 1987. 'I Was My Parents' Radio.' Glamour Magazine, May.

Preston, P. 1995 Mother Father Deaf: Living Between Sound and Silence, Cambridge, Mass.: First Harvard University Press. 